\title{
PENANAMAN PENDIDIKAN AKHLAK PADA ANAK USIA DINI \\ MENURUT IBNU MISKAWAIH DALAM KITAB TAHDZIBUL AKHLAK
}

\author{
Riami $^{1}$ \\ Devy Habibi Muhammad ${ }^{2}$ \\ Ari Susandi ${ }^{3}$ \\ Sekolah Tinggi Agama Islam Muhammadiyah Probolinggo \\ Email: riamiabi6@gmail.com.
}

\begin{abstract}
Education is the process of internalizing knowledge and children or students. However it is not only that which needs to be conveyed by educators and parents, the issue of morality or character is also very important to instill. Moral education is the basis for growing an efficient generation.Moral Education must be instilled early,because at this stage children have a greater capacity to absorb a certain stimuli. Educators must be able to use the best way to develop ideal moral education in order to succeed in moral education. In fact,they must understand the attitudes that need to be taken to complete the implementation and indoctrination of moral education for early childhood.This research uses literature study and qualitative descriptive analysis.According to Ibn Miskawaih this research has the aim of fostering students with good moral and moral qualities. Acquire sufficient knowledge through training and practice.
\end{abstract}

Keywords:Moral,Early Childhood,Ibnu Miskawaih,Tahdzibul Akhlak Book

\begin{abstract}
Abstrak
Pendidikan adalah proses internalisasi pengetahuan pada anak-anak atau peserta didik. Namun, bukan hanya itu juga yang perlu disampaikan oleh pendidik dan orang tua, masalah moral atau karakter juga sangat penting untuk di tanamkan. Pendidikan moral merupakan dasar untuk menumbuhkan generasi yang efisien. Pendidikan moral harus ditanamkan lebih awal, karena pada fase ini anak mempunyai kapasitas yang lebih besar untuk menyerap suatu rangsangan tertentu. Pendidik harus dapat menggunakan cara yang terbaik untuk mengembangkan pendidikan moral yang ideal agar berhasil dalam pendidikan moral.Bahkan, mereka harus memahami sikap yang perlu dilakukan untuk melengkapi implementasi dan indoktrinasi pendidikan moral bagi anak usia dini. Penelitian ini menggunakan studi kepustakaan dan analisa deskriptif kualitatif. Adapun penelitian ini menurut Ibnu Miskawaih mempunyai tujuan untuk membina peserta didik dengan kualitas akhlak dan akhlak yang baik. Memperoleh pengetahuan yang cukup melalui pelatihan dan praktek.
\end{abstract}

Kata kunci :Akhlak,Anak Usia Dini,Ibnu Miskawaih,Kitab Tahdzibul Akhlak

\footnotetext{
${ }^{1}$ Mahasiswa STAI Muhamadiyah Probolinggo

${ }^{2}$ Dosen STAI Muhamadiyah Probolinggo

${ }^{3}$ Dosen STAI Muhamadiyah Probolinggo

10| Falasifa, Vol. 12 Nomor 2 September 2021
} 

Riami

Devy Habibi Muhammad

Ari Susandi

\section{PENDAHULUAN}

Pendidikan merupakan sesuatu yang penting dalam kehidupan kita sehari -hari. Tujuan utama pendidikan adalah membimbing manusia menuju kehidupan yang lebih baik dan melatih manusia yang bermutu untuk meraih kesuksesan di masa depan. Pendidikan yang di berikan jangan di anggap remeh,harus komprehensif dan mencakup semua aspek perkembangan siswa. Pengaruh globalisasi telah memperburuk situasi di Indonesia. Sistem Pendidikan Indonesia gagal menghentikan kecenderungan menuju globalisasi.(Mufarohah et al., 2018).

Pendidikan juga merupakan suatu sistem yang dapat diikuti dan dipahami oleh setiap individu dengan melihat dan mengembangkan segala imajinasi dan potensi yang ada pada diri orang tersebut untuk benar-benar membekali dirinya. Pendidikan merupakan aspek kehidupan yang sangat penting bagi diri sendiri, keluarga dan masyarakat,serta membantu meningkatkan kualitas hidup. Pendidikan juga merupakan upaya seseorang untuk meningkatkan pengetahuan, keterampilan dan memperluas wawasannya.(Nur khosiah, 2019)

Pendidikan adalah suatu sistem yang dapat diikuti dan dipahami oleh setiap orang, yang dengan memperhatikan dan mengembangkan segala daya khayal dan potensi internalnya, bertujuan untuk merangsang diri menjadi individu yang berdaya saing dan berdaya cipta kuat, guna meningkatkan mutu pendidikan. Selain itu,sebenarnya merupakan salah satu acuan bagi semua orang untuk saling berkomunikasi antara satu dengan orang lain, dan orang lain akan memberikan mereka kondisi untuk memupuk dan mengembangkan kehidupan sosial.(Susandi, 2020)

Pendidikan juga merupakan suatu sistem yang dapat diikuti dan dipahami oleh setiap individu dengan melihat dan mengembangkan segala imajinasi dan potensi yang ada pada diri orang tersebut untuk benar-benar membekali dirinya. oleh karena itu,Peran pendidikan sebagai agen perubahan adalah mengubah orang yang tidak beradab menjadi orang yang beradab, atau mengubah orang yang berperilaku buruk menjadi orang baik. Sosiolog Pierre Bourdieu mengatakan bahwa pendidikan adalah reproduksi budaya. Medianya (Pierre Bourdieu). Ini berarti bahwa pendidikan "memainkan peran penting dalam reproduksi masyarakat dan kelas sosial yang terus mengikuti.(Hidayah, 2018)

Seperti yang dikutip Ibnu Miskawi dalam "Abdul Majid” dan "Diane Andayani”, pendidikan akhlak merupakan upaya untuk mencapai sikap spiritual yang secara spontan dapat mendorong lahirnya seseorang perbuatan baik manusia. Dalam pendidikan akhlak semacam ini, standar penilaian perilaku yang benar dan salah.Di sini,Agama Islam menyampaikan informasi moral terkait pendidikan anakanaknya kepada orang tua. Orang tua harus membesarkan anak-anak dan membimbing mereka ke jalan yang benar, dan membekali mereka dengan aturan-aturan moral, sehingga dapat membimbing mereka menjadi anak-anak yang bangga akan hadirat Tuhan.(hadisa putri, 2016) 
Masa awal kehidupan merupakan masa penting untuk pertumbuhan dan perkembangan anak yaitu sebagai masa emas (golden age). Banyak psikolog menyarankan untuk mengoptimalkan anak karena itu hanya akan terjadi sekali dalam proses tumbuh kembang anak.Tahun-tahun awal dikenal sebagai tahap kritis perkembangan anak.karena jika anak tidak mendapatkan kasih sayang yang cukup dalam pendidikan akhlak, perawatan dan pelayanan kesehatan serta kebutuhan gizinya saat ini, saya khawatir anak tidak akan mendapatkan pertumbuhan dan perkembangan yang terbaik.(Juwita, 2018) Kunci pembentukan kepribadian anak dalam proses pendidikan tercantum dalam Al-Qur'an yang menjelaskan bahwa anak dilahirkan dengan sifat-sifat yang baik. Mereka percaya bahwa kualitas yang baik akan mempengaruhi kepentingan praktis dari model pembelajaran yang akan diterapkan dalam pengajaran.(Muhammad et al., 2021) Selanjutnya, peran orang tua tidak kalah penting dalam posisi ini karena lingkungan utama mereka tumbuh dan belajar untuk memperbarui adalah orang tua. (Santoso et al., 2020)

Selanjutnya,pendidikan memegang peranan penting dalam sosialisasi akhlak kepada siswa, diperlukan sistem pendidikan yang berkualitas dan sesuai dengan waktu. Karena alasan ini, perlu untuk mereformasi pendidikan, di mana pendidikan harus seimbang antara tujuan duniawi dan ukhrawy dan mereka lebih mementingkan pembentukan moral pada siswa diperlukan. Pembentukan moral kepada siswa-siswa ini harus sama antara dimensi rasional (etika sikap) dan dimensi agama murni (etika agama), sehingga hasil akhir pendidikan direncanakan untuk menjangkau orang-orang yang memiliki kecerdasan tinggi dan mapan sikap, sains dan amal. dilakukan seimbang. (SORTA MANURUNG, 2015) Ketuhanan dan nilai-nilai kemanusiaan adalah dua aspek yang tidak terpisahkan dari kehidupan beragama.(benny prasetya, M.Usman, 2004)

Menurut Ibnu Miskawaih dalam Kitab Tahdzibul Akhlak bahwa tujuan pendidikan moral adalah untuk membina siswa-siswi yang berilmu dan beretika yang baik melalui latihan serta kebiasaan. Pemikiran-pemikiran akhlak Ibnu Miskawi sangat berkaitan sebagai pola pelengkap bagi penanaman pendidikan akhlak anak-anak zaman modern awal, karena pemikiran-pemikiran Ibnu Miskawi tentang doktrin wasatiyah tidak hanya berubah-ubah akan tetapi mudah di atur sesuai aturan yang ada. Oleh karena itu, pengaruh ini harus diterapkan sesuai dengan kemajuan zaman sekarang tanpa menghilangkan nilai penting dari pendidikan moral itu sendiri.(muktazzah fiddini, 2007)

Oleh karena itu, untuk lebih memahami pendidikan moral usia dini, Ibnu Miskawai mempunyai berbagai ekspresi tentang masalah dan tujuannya, antara lain memahami pendidikan akhlak usia dini dan bagaimana tujuan pendidikan akhlak Ibnu Miskawai dapat dicapai. Miskawaih, memahami dan memahami arti penting dan tujuan pendidikan akhlak usia dini. 
Riami

Devy Habibi Muhammad

Ari Susandi

\section{KAJIAN TEORI}

\section{Pendidikan Akhlak}

Menurut Ibnu Maskawih,moral tertanam dalam jiwa yang mendorongnya untuk bertindak tidak berpikir atau mempertimbangkan. Akhlak mulia adalah tanda iman yang sempurna. Semakin kuat keimanan seseorang maka semakin baik akhlaknya, begitu juga sebaliknya. Kemuliaan akhlak manusia tidak hanya vertikal, yaitu hubungan baik dengan Allah Ta'ala, tetapi juga horizontal. Anda dapat melihat betapa baiknya hubungan dengan manusia lain dan bahkan dengan makhluk Tuhan lainnya seperti hewan dan tumbuhan dalam komunikasi sehari-hari. Untuk manfaat kebaikan moral.(Suhartono, 2019)

Pendidikan akhlak merupakan upaya mencapai sikap jiwa yang memotivasi seseorang untuk secara wajar menghasilkan perilaku yang bernilai. Dalam menilai perilaku yang terjadi,Al-Qur'an dan Hadits merupakan sumber tertinggi ajaran Agama Islam. Dalam hal ini, pendidikan moral disebut pendidikan akhlak dalam wacana pendidikan Islam.(Prasetiya, 2018)

Tujuan pendidikan akhlak yang dirumuskan oleh Ibnu Miskawaih adalah untuk melatih perilaku batin, yang secara otomatis dapat memajukan semua perilaku dengan nilai-nilai yang baik. Oleh karena itu, perlu untuk mencapai kesempurnaan dan memperoleh kebahagiaan yang hakiki, sempurna dan menyeluruh, termasuk kebahagiaan pribadi dalam arti yang seluas-luasnya.(Miswar, 2021)

\section{Pendidikan Anak Usia Dini}

Kamus Besar Bahasa Indonesia, pendidikan merupakan proses mengubah sikap atau perilaku seseorang atau sekelompok agar menjadi orang dewasa dengan melakukan pengajaran dan pelatihan. Oleh karena itu,pendidikan adalah segala bentuk pengalaman belajar yang berlangsung di lingkungan rumah, sekolah, dan masyarakat dengan tujuan untuk mengembangkan keterampilan dengan sebaikbaiknya sejak lahir sampai akhir hayat.Untuk meningkatkan sikap dan perilaku tersebut maka pendidikan karakter harus diimplementasikan mulai sejak dini (Yulianto \& Prasetiya, 2019)

Pendidikan anak usia dini adalah jenjang pendidikan sebelum jenjang pendidikan dasar yang memberikan penyuluhan kepada anak sejak lahir sampai dengan usia enam tahun dan memberikan nasehat pendidikan yang menunjang pertumbuhan dan perkembangan jasmani. Mempersiapkan anakanak untuk pendidikan tinggi. Kepmen No. 20 Tahun 2003 menjelaskan tentang Sistem Pendidikan Nasional yang menyatakan bahwa bangsa Indonesia berkomitmen untuk menyelenggarakan pendidikan anak usia dini, yaitu sejak lahir sampai dengan enam tahun (2006). Bhawani berpendapat anak usia dini merupakan masa umur yang sangat muda. yang dimaksud adalah anak yang mengalami masa kanakkanak pertama,yaitu antara usia 0 sampai enam tahun, yang akan mengembangkan kemampuan emosional dan lebih cenderung memiliki kecerdasan ketika dewasa. Oleh karena itu,dapat dilihat dari 
penjelasan di atas bahwa pendidikan usia dini merupakan jenjang pendidikan yang cukup unik serta makna hukum pertumbuhan dan perkembangan bagi kelompok usia 0-6 tahun dalam proses tumbuh kembang. Melalui proses perkembangan fisik baik motorik halus maupun kasar, kecerdasan, socialemosional, bahasa dan komunikasi, khusus untuk pencapaian tumbuh kembang .(sukarno l.hasyim, 2018)

\section{METODOLOGI PENELITIAN}

Penelitian kepustakaan mengacu pada penelitian yang dilakukan dengan mempelajari literatur tentang masalah penelitian dalam buku, manuskrip, atau jurnal. Semua informasi berasal dari teks tertulis dan dokumen lain yang berhubungan dengan pertanyaan penelitian. (Harimulyo et al., 2021) penelitian ini menggunakan analisis deskriptif kualitatif dengan mengkaji dari jurnal penelitian dan berbagai referensi(Susandi, 2020) Tidak hanya itu,penelitian ini terpaut dengan pengembangan rancangan pembelajaran adab anak umur dini yang dipaparkan oleh Ibnu Miskawaih.penelitian ini merujuk pada prinsip pembelajaran kepribadian pada pembelajaran anak umur dini yang diterbitkan oleh Panitia PAUD serta kesusastraan mengenai pembelajaran akhlak anak umur dini bersumber pada Tahdzib Al- akhlak buatan Ibnu Miskawaih.

Teknik analisis yang digunakan adalah metode deskriptif. Metode deskriptif adalah mengambil data melalui klarifikasi berdasarkan data hasil penelitian. Karena teknik analisis seharusnya memudahkan pembaca untuk memahami dan menerapkan konten.(Fauziyah et al., 2021) Penelitian ini mendefinisikan pembelajaran akhlak dialektika dalam pemikiran Ibn Miskawaih (Prasetiya, 2018)

\section{PEMBAHASAN DAN HASIL}

\section{Biografi Ibnu Miskawaih}

Ibnu Miskawi adalah seorang filosof Islam yang sangat tertarik dengan etika. Nama lengkapnya adalah Abu Ali Ahmed bin Mohammed bin Yakubu bin Miskawi. Ia lahir di Rai, Iran pada tahun 330 M/941 M dan meninggal pada tahun 2009. Syafar 421/16 tahun.Itu di Casfahan pada Februari 1030 M. Nama Miskawaih diambil dari nama kakeknya.Kakeknya kemudian masuk Islam. Gelarnya, Abu Ali, nama seorang sahabat dari Ali, dianggap sebagai sosok yang berhak menggantikan nabi dalam kepemimpinan umat Islam setelahnya. Dengan gelar ini, kebanyakan orang akan mengatakan bahwa dia adalah Syiah. Dan gelarnya adalah alKhazim yang artinya chief financial officer, karena dipercaya sebagai chief financial officer di bawah pimpinan Adid al Daulah Bani Buwaih.

Ibnu Miskawaih adalah seorang sejarawan, terapis, ilmuwan dan penulis yang telah mempelajari berbagai ilmu dan akhirnya fokus pada studi sejarah dan etika. Gurunya dalam bidang sejarah adalah Abu Bakar Ahmad bin Kamil al-Qadhi, dan dalam bidang filsafat adalah Ibnu al-Khammar. Selama 
Riami

Devy Habibi Muhammad

Ari Susandi

beberapa dekade, beberapa menteri dan emir pustakawan Bani Buwaih, yaitu: Menteri Baghdad Hasan al-Mahlabi (348352 H), Menteri Rayy Abu al-Fadhi Muhammad ibn al-Amid (352360 H), Menteri Abu al Fadl Ibn Mohammed di Rayy (360366H). ), iklan Emir Daula ibn Buwaih lainnya di Baghdad (367373 H) dan sejarah pendidikan beberapa Emir Emir Ibn Miskawaih lainnya tidak diketahui, dan dia tidak menulis otobiografi. Dikatakan bahwa Ibnu Misavai tidak berbeda dengan anak-anak biasa. Maftuhin mengutip Ahmad Amin yang mengatakan bahwa selama dinasti Abbasiyah, membesarkan anak biasanya dimulai dengan membaca, menulis, belajar Al-Qur'an, pengetahuan dasar bahasa Arab, aturan puisi, dan mengetahui cara membaca dan menulis puisi. Bahan-bahan ini diserahkan ke Surau.

Ibnu Miskawaih disebut mu'allim althālith atau guru ketiga setelah al-Farābī dan Aristoteles karena telah menguasai logika dan filsafat Yunani. Ia hidup pada masa ketika suasana spiritual mencapai puncaknya pada masa pemerintahan Abbas. Penerjemahan bahasa Arab karya asing, khususnya karya Yunani, saat ini sedang ditingkatkan, dan Bait al-Hikmah juga ditingkatkan sebagai pusat penerjemahan dan khazanah ilmu pengetahuan. Dalam 20 tahun terakhir hidupnya, Misichuan lebih aktif menulis daripada dia masih kecil. Tahdhīb al Akhlak adalah buku yang sangat berkesan, ditulis ketika dia berusia 80 tahun.

\section{Konsep Akhlak Ibn Miskawaih}

Ibn Miskawaih menggambarkan rancangan pembelajaran akhlak yang hebat dalam ciptaannya bertajuk Tahzib Al-akhlâq.Beliau menekankan kalau etika merupakan kondisi jiwa serta suasana ini menimbulkan kelakuan jiwa tanpa didesain serta dikira terlebih dulu. Ia memilah asal mula jiwa ini jadi 2 tipe, ialah kepribadian natural serta dilahirkan lewat kebiasaan serta bimbingan. Menurutnya, karakternya alami, tetapi moralitas juga bisa berganti dengan cepat atau lamban melalui ajakan dan nasihat yang baik. Pada awal mulanya, situasi ini terjalin sebab dianggap dan dikira, oleh karena itu lewat bimbingan berkelanjutan itu terbentuklah moral. Oleh sebab itu, sangat sesuai dengan definisi,moralitas usia dini akan menjauhi karakternya dan bisa berganti dengan pelatihan serta kebiasaan.(ahmad wahyu hidayat, n.d.)

Ibnu Miskawi memaparkan rancangan pembeljaran adab dengan cara besar dalam bukunya Tahzib al-Akhlâq. Dalam buku ini,beliau menyatakan moralitas adalah kondisi jiwa yang menimbulkan jiwa berperan tanpa berpikir.Dia memilah asal ide kondisi jiwa ini jadi 2 tipe: natural serta berawal dari kepribadian, dan kerutinan serta buatan efisien.Pada awal mulanya kondisi ini terjalin sebab estimasi serta pandangan,namun lewat bimbingan yang lalu menembus hendak jadi akhlak. Menurutnya,akhlak itu fitrah, tetapi akhlak cepat atau lambat akan berubah melalui kedisiplinan dan nasehat yang baik.awal mulanya kondisi ini disebabkan karena pertimbangan serta pemikiran, tetapi dengan latihan yang rutin 
akan menjadi moral. Oleh karena itu, menurut definisi ini, moral anak-anak muda dimulai dengan karakter dan dapat diubah melalui latihan dan kebiasaan.(Rosnita, 2013)

\section{Tujuan Pendidikan Akhlak}

Tidak hanya itu Ibnu Miskawaih juga dikenal selaku bapak etika atau moralisme Islam karena menitikberatkan pada moralitas. Melalui pendidikan akhlak, Miskawi telah menetapkan tujuan, yaitu mencapai sikap batin yang secara spontan dapat mendorong segala perbuatan baik, mencapai kesempurnaan dan memperoleh kebahagiaan sempurna sejati. Moralitas merupakan salah satu landasan filsafat pendidikan Ibnu Miskawi. Dia mengusulkan moralitasnya berdasarkan doktrin selalu. Secara umum, ia mendefinisikannya sebagai keseimbangan antara dua ekstrem, tengah, harmoni, utama, mulia atau posisi tengah. Namun, ia cenderung berargumen bahwa kebajikan moral biasanya ditafsirkan sebagai suatu tempat antara ekstrem dari jasa dan ekstrem dari cacat setiap jiwa manusia.

Filosofi pembelajaran akhlak Ibnu Miskawaih pada dasarnya merupakan membina orang yang cerdas, simple, berani serta seimbang agar bahagia. Oleh karena itu, pribadi ideal Ibnu Miskawi adalah seseorang yang bisa memposisikan dirinya dengan cara sepadan serta handal dalam konteks yang seimbang serta selalu berada di tengah ekstrem kehidupan.(Muthoharoh, 2014)

Menurut karya Ibnu Miskawaih, pendidikan akhlak setidaknya memiliki tiga tujuan. Bab Pertama mencetak perilaku manusia yang baik agar manusia dapat bertindak dengan sopan serta sempurna cocok dengan bakat orang. kedua. Beliau mengangkat derajat orang dari tingkatan yang sangat hina ke tingkatan yang dilaknat oleh Allah SWT. ketiga.Memimpin orang jadi orang sempurna ( alinsân alkâmil). Dalam kondisi ini, tujuan pembelajaran adab pada anak adalah meningkatkan serta membuat adab agung pada diri anak, alhasil jadi orang yang sempurna,serta anak menjadi orang yang bermoral agung di hadapan Allah SWT.(Rosnita, 2013) Ibn Miskawih dalam pemikirannya tentang etika, mulai mengeksplorasi jiwa manusia.Dia melihat bahwa ilmu psikologi memiliki kebajikannya sendiri dibandingkan dengan sainsnya yang lain. Manusia tidak dapat mencapai sains, kecuali untukmengenali ilmu jiwa tadinya. Kala seorang menguasai ilmu jiwa, hingga itu jadi dorongan buat memperoleh wawasan lain. Oleh sebab itu dari bermacam bidang modul serta tujuanya hingga dikelompokkan jadi 3 bagian ialah empirik untuk pendatang baru, logik untuk menengah serta etik untuk besar.(ahmad wahyu hidayat, n.d.)

\section{Pembentukan Akhlak Anak Usia Dini}

Usia dini adalah momen sangat penting dalam perkembangan dan kemajuan anak.tidak hanya perkembangan otak anak yang cepat, tahun-tahun awal biasanya disebut juga dengan masa keemasan, dimana pada masa ini segala rangsangan terhadap segala aspek perkembangan memegang peranan 17| Falasifa, Vol. 12 Nomor 2 September 2021 
Riami

Devy Habibi Muhammad

Ari Susandi

penting dalam tumbuh kembang anak selanjutnya.Bagi Santrock,pada umur 2 tahun, kemajuan otak kanak- kanak menggapai dekat 75\% dari dimensi otak orang berusia. Pada dikala yang serupa, pada umur 5 tahun, kemajuan otak kanak- kanak merupakan 90\% dari dimensi otak orang berusia. Santrock merumuskan kalau langkah dini ini ialah momen kritis untuk kemajuan otak, intelek, serta keahlian berlatih anak.(Juwita, 2018)

Dalam Hukum Sisdiknos No.Pasal 28 Uraian Sekretaris,menerangkan kalau pembelajaran dini dicoba saat sebelum tingkatan pembelajaran dasar lewat pembelajaran Resmi( sekolah), non resmi( komunitas) serta informal( keluarga). Pendidikan anak diselenggarakan sejak lahir kepada anak-anak berusia 6 tahun. Dalam pembelajaran anak usia dini ini, diharapkan semua kemungkinan semua anak bisa mengembangkan potensinya baik secara fisik maupun batin.

Pada periode ini, pembentukan moral anak-anak sangat penting. Karena pendidikan keluarga tidak dapat membuat perannya ketika menempatkan karakter mulia awal, jumlah lembaga pendidikan untuk mencapai tujuan pendidikan nasional. Mungkin itu bukan ketika seorang anak tumbuh, tetapi dari hari-hari pertama untuk anak-anak,karakter uangnya mulai diajarkan oleh anak-anak. Dalam hal ini, Ibn Miskawai menerima panduan untuk pendidikan moral masa kanak-kanak .Menurutnya,baik pendidik,orang berumur serta guru wajib menguasai kalau jiwa anak itu semacam kaitan antara jiwa orang serta intelek. Dalam jiwa anak, jiwa binatang telah selesai, namun jiwa orang mulai timbul. Oleh sebab itu, kanak- kanak wajib dididik dengan membiasakan urutan lembaga pemerintah anak-anak, yaitu, keinginan, kekuatan marah dan kekuatan pemikiran. Dengan kekuatan hasrat, anak-anak di didik dalam hal tata cara makan, minum, dan berpakaian. (Rosnita, 2013)

Berdasarkan uraian tersebut, sedemikian itu beratnya kewajiban seseorang pengajar paling utama orang berumur dalam menciptakan angkatan yang bermoral agung. Dengan sedemikian itu beratnya kewajiban dalam melindungi anak hingga orang berumur hendak mendapatkan balasan yang cocok bila ceria anak dengan bagus. Salah satu metode buat menanggulangi permasalahan ini merupakan dengan membagikan pembelajaran moral yang baik kepada anak-anak. Pendidikan akhlak memerlukan kerjasama orang tua dan guru di sekolah yaitu pendidikan akhlak khususnya pendidikan akhlak islam harus menyampaikan rasa tanggung jawab akhlak terhadap anak sejak dini disamping menciptakan tanggung jawab akhlak terhadap anak. Generasi yang berperilaku (moral) baik untuk kenyamanan, kedamaian dan kebahagiaan hidup ini dan selanjutnya.(Herawati, 2017)

Dalam penanaman dan pembentukan akhlak anak, terutama pada usia ini, sangat perlu diperhatikan dan dikembangkan secara maksimal, baik itu pengucapan, gerak maupun tingkah laku. 


\section{KITAB TAHDZIBUL AKHLAK}

Buku Tahdzibul akhlaq Wa Tathir al- A“eraq yakni terwujudnya pribadi kesusilaan, berkelakuan yang lahir dari padanya perilaku- perilaku terhormat, ataupun adib akhlak agung. Buat menggapai anganangan ini haruslah lewat pembelajaran serta buat melakukan pembelajaran butuh mengenali karakter orang ataupun budi peketri orang. Khulq( karakter) ialah sesuatu situasi untuk jiwa yang mendesak buat menciptakan aksi laris tanpa fikir serta estimasi( aksi laris otomatis). Situasi ini dibagi 2, yang natural dari asal mizaaj( temperament). Kedua yakni karakter seseorang yang didapat dari kerutinan dengan bimbingan yang berkali- kali. Jadi karakter pula bisa dilatih dengan perbuatan- perbuatan yang bagus alhasil menciptakan karakter yang lebih baik.(Dina khairiah, 2021)

Ibnu Miskawaih melaporkan kalau arti buku Tahdzib al- Akhlak dijadikan prinsip untuk kemajuan adab. Ia berkata kalau tujuan penyusunan kitab ini merupakan untuk menghasilkan etika dalam diri sendiri, etika hendak jadi pangkal aksi,kesemuanya akan menjadi baik atau indah, bukan karena diciptakan atau dipaksakan,semua perilaku ini keduanya dapat dicapai secara sistematis melalui rekayasa dan pendidikan. Sehingga dapat diketahuikalau bagi Ibnu Miskawaih, pembelajaran adab bisa ditingkatkan lewat bimbingan ataupun kerutinan. Berlainan dengan buku- buku Ibnu Miskawaih yang lain yang pula mengulas permasalahan akhlak, dalam buku ini Ibnu Miskawaih lebih fokus pada keahlian jiwa, pembinaan ataupun pembelajaran adab, serta metode dan psikologi akhlak Islami.Kitab Tahdzibul akhlak initerdiri dari 7 bab, bab pertama mengulas hal jiwa, sebab jiwa ialah pusat tempat tampaknya adab; bab kedua mangulas mengenai adab, di ayat ini Ibnu Miskawaih mengawalinya dengan penerangan arti dari adab itu sendiri, setelah itu terdapat ulasan mengenai bakat orang; bab ketiga mangulas bagian penting dari adab ialah kebaikan serta aib dan keceriaan;bab keempat mangulas mengenai keistimewaan yang muat permasalahan kesamarataan; bab kelima berdialog hal cinta serta pertemanan; 2 bab terakhir mangulas mengenai kesehatan jiwa serta pengobatan penyakit jiwa.(Muthoharoh, 2014)

Dalam buku Tahzîb al- Akhlâq, Ibn Miskawaih pula membagikan arti dari 4 keistimewaan itu, serta bermacam berbagai dari keempat keistimewaan itu. Awal. Kebajikan merupakan keistimewaan dari jiwa berasumsi serta mengenali. Kebajikan ini mempunyai bagian- bagian semacam cerdas, ingat, berasumsi, kilat menguasai serta betul pemahamannya, bening benak, dan sanggup berlatih dengan gampang. Kedua. Simpel merupakan keistimewaan dari bagian hawa hasrat. Ketiga. Kegagahan merupakan keistimewaan jiwa kemarahan. Kegagahan ini dipecah jadi sebagian bagian, ialah besar jiwa, rajin, kuat, sabar, memahami diri, bagak dan rajin dalam bertugas. Simpel ini mempunyai bagian- bagian ialah rasa malu, hening, ikhlas hati, integritas, puas, patuh, berdisiplin diri, optimis, kelembutan, ayu 19| Falasifa, Vol. 12 Nomor 2 September 2021 
Riami

Devy Habibi Muhammad

Ari Susandi

berkarisma serta warak. Keempat. Kesamarataan merupakan kebajikan jiwa yang mencuat dampak menyatunya 3 kebajikan itu.(Rosnita, 2013)

Dari uraian di atas bisa disimpulkan kalau pembelajaran adab Ibnu Miskawi amat besar serta mendalam. Dalam novel ini, Tazb Ibn Miskawi pula menyangkal sebagian pandangan Yunani kalau etiket tidak bisa diganti sebab berawal dari kepribadian serta dorongan hati. Menurutnya, adab senantiasa dapat diganti dengan kerutinan bagus, bimbingan serta bimbingan. Sebab beberapa besar kanak- kanak hidup serta dididik dengan metode khusus dalam warga, nyatanya terdapat perbandingan yang penting dalam pendapatan mereka kepada nilai- nilai akhlak yang amat terhormat. Oleh sebab itu, orang bisa membenarkan akhlaknya dengan melenyapkan seluruh sifat- sifat yang mengganggu serta menghiasinya dengan sifat- sifat yang baik serta agung. Ini pula merupakan tujuan penting dari anutan agama, ialah buat menancapkan sebagian angka akhlak yang besar serta membuat orang jadi bagus serta senang Ini juga merupakan tujuan utama dari ajaran agama, yaitu untuk menanamkan beberapa nilai moral yang tinggi dan membuat orang menjadi baik dan bahagia.Jadi,Penanaman Pembelajaran Adab pada anak umur dini amat berarti di ajarkan dan di biasakan kepada anak yang masih dini baik secara pembiasan maupun macam keutamaan yang di terapkan Ibnu Miskwaih agar pembentukan akhlak menjadi lebih terarah dan tercapai dengan baik di masa depan.

\section{KESIMPULAN}

Dari perspektif pendidikan Islam, rancangan pembelajaran kepribadian( adab) sudah lama dirintis oleh Ibnu Miskawaih.Dalam perihal ini, mengingat nilai-nilai akhlak Ibnu Miskawi sudah lama diketahui oleh para pendidik muslim, seharusnya lembaga pendidikan Islam ikut berperan dalam membentuk karakter anak negeri. Namun ide tersebut belum terealisir dengan baik,Alhasil pembelajaran pendidikan Islam modern belum begitu berhasil dalam membina siswa yang berkarakter.

Uraian Ibnu Miskawaih tentang pembentukan akhlak anak usia dini memberikan pelajaran bahwa pendidik,orang tua,guru serta mukmin wajib sanggup menerapkan serta memahami adab yang baik kepada anak semenjak dini.Pendidik harus terlebih dulu memahami fitrah psikologis anak,kemudian mulai mengajarkan, mengindoktrinasi dan membiasakan diri dengan akhlak mulia. Fokus pemikiran Ibnu Miskawi adalah sangat penting bagi pendidik untuk mendidik,menasehati ,mengamalkan, mendisiplinkan, menghukum dan memberi penghargaan pada anak semenjak dini.Dalam perihal ini pengajar wajib mulai ceria serta mengenalkan adab agung anak, menghindari adab jelek, membiarkan anak mulai mentaati syariat agama, serta tidak membiarkan anak hidup dengan orang yang tidak bermoral. Ceria anak semenjak dini hendak lebih sukses dari ceria anak di umur anak muda. 
Penanaman Pendidikan Akblak Pada Anak Usia Dini

\section{DAFTAR PUSTAKA}

Ahmad Wahyu Hidayat, Ulfa Kesuma. (N.D.). ANALISIS FILOSUFIS PEMIKIRAN IBNU MISKAWAIH (SKETSA BIOGRAFI, KONSEP PEMIKIRAN PENDIDIKAN, DAN RELEV ANSINY A DIERA MODERN). 148(1), 148-162.

Benny Prasetya, M.Usman, M. F. S. H. (2004). Analisas Jurnal Studi Keislaman. 20(1), 95-108.

Dina Khairiah, A. Wardhana Manalu. (2021). Filsafat Paud: Kajian Akblak Menurut Ibnu Miskawaih. 1(1), $1-15$.

Fauziyah, M., Prasetiya, B., \& Khosiah, N. (2021). Konsep Pendidikan Akhlak Luqmanul Hakim ( Kajian Tafsir Al-Misbah Dan Al-Maraghi ). Jurnal Penelitian Ipteks, 6(1), 52-61. Https://Doi.Org/10.32528/Ipteks.V6i1.5251

Hadisa Putri. (2016). Konsep Pendidikan Anak Usia Dini Dalam Perspektif Islam. Studi Islam Dan Humaniora, Xiv(Khazanah), 1-24.

Harimulyo, M. S., Prasetiya, B., \& Muhammad, D. H. (2021). Nilai-Nilai Pendidikan Akhlak Dalam Kitab Risalatul Mu'awanah Dan Relevansinya. Jurnal Penelitian IPTEKS, 6(1), 1-18. Https://Doi.Org/10.32528/Ipteks.V6i1.5253

Herawati. (2017). Pendidikan Akhlak Bagi Anak Usia Dini. Bunayya: Jurnal Pendidikan Anak, 3(2), 1-13.

Hidayah, U. (2018). Rekonstruksi Evaluasi Pendidikan Moral Menuju Harmoni Sosial. Jurnal Pedagogik, 05(01),

69-81.

Https://Ejournal.Unuja.Ac.Id/Index.Php/Pedagogik\%0apermata_Ulya@Yahoo.Co.Id

Juwita, D. R. (2018). Pendidikan Akhlak Anak Usia Dini Di Era Millennial. Ilmu Tarbiyah, 7(2), $282-314$.

Miswar, M. (2021). Konsep Pendidikan Akhlak Menurut Ibnu Miskawaih. In Al-Fikru: Jurnal Ilmiah (Vol. 14, Issue 1). Https://Doi.Org/10.51672/Alfikru.V14i1.32

Mufarohah, L., Mujahidin, E., \& Alim, A. (2018). 12 Pendidikan Akhlak Untuk Anak Usia Dini. Prosiding Bimbingan Konseling, 1-7.

Muhammad, D. H., Deasari, A. E., \& Dirgayunita, A. (2021). Pendidikan Anak Usia Dini Berbasis Psikologi Islam. Jurnal Pendidikan Islam Al-Ilmi, 4(1), 1-13. Https://Doi.Org/10.32529/AlIlmi.V4i1.821

Muktazzah Fiddini. (2007). Konsep Pendidikan Akblak. Menurut Ibnu Miskawaih (Studi Kitab Tabdrib AlAkblak).

Muthoharoh. (2014). Konsep Dan Strategi Pendidikan Akhlak Menurut Ibnu Miskawaih Dalam Kitab Tahdzib Al-Akhlak. Skripsi, 89-106. Http:/ /Eprints.Walisongo.Ac.Id/5416/1/103111076.Pdf

Nur Khosiah. (2019). Pelaksanaan Pendidikan Karakter Di M.I. Miftahul Ulum Tambakrejo Tongas Probolinggo. Paper Knowledge . Toward A Media History Of Documents, Xvii, 1-11.

Prasetiya, B. (2018). Dialektika Pendidikan Akhlak Dalam Pandangan Ibnu Miskawaih Dan Al-Gazali. Intiqad: Jurnal Agama Dan Pendidikan Islam, 10(2), 1-19. Https://Doi.Org/10.30596/Intiqad.V10i2.2381

Rosnita, R. (2013). Pembentukan Akhlak Anak Usia Dini Menurut Ibn Miskawaih. MIQOT: Jurnal IlmuIlmu Keislaman, 37(2), 1-19. Https://Doi.Org/10.30821/Miqot.V37i2.89

Santoso, D. A., Suparman, T., \& ... (2020). Peran Orang Tua Dalam Meningkatkan Motivasi Belajar Siswa Di Sekolah Dasar. Jurnal Kependidikan Dasar Islam Berbasis Sains, 6(1), 84-91. Http://Journal.Ubpkarawang.Ac.Id/Mahasiswa/Index.Php/IJPSE/Article/View/58

SORTA MANURUNG. (2015). Pemikiran Ibn Miskawaih Tentang Pendidikan Akblak.

Suhartono, N. Latifah. (2019). Pendidikan Akblak Pada Anak Usia Dini. 1, 1-23.

Sukarno L.Hasyim. (2018). Pendidikan Anak Usia Dini (PAUD) Dalam Perspektif Islam Oleh: Sukarno L. Hasyim 1.1-9.

Susandi, A. (2020). Implementasi Kecerdasan Majemuk Di Sekolah Dasar. Fundamental Pendidikan Dasar,

21| Falasifa, Vol. 12 Nomor 2 September 2021 
Riami

Devy Habibi Muhammad

Ari Susandi

3(3), 260-271.

Yulianto, A., \& Prasetiya, B. (2019). Analisis Interaksi Adab Seorang Murid Terbadap Guru Dalam Perspektif Imam Al-Gharali. 1-11. 